\title{
Calculation of Physiologic Dead Space: Comparison of Ventilator Volumetric Capnography to Measurements by Metabolic Analyzer and Volumetric $\mathrm{CO}_{2}$ Monitor
}

\author{
Mark S Siobal RRT FAARC, Hannah Ong RRT, Josephine Valdes RRT, and Julin Tang MD
}

\begin{abstract}
BACKGROUND: Calculation of physiologic dead space (dead space divided by tidal volume [ $\mathrm{V}_{\mathrm{D}} /$ $\left.V_{T}\right]$ ) using the Enghoff modification of the Bohr equation requires measurement of the partial pressure of mean expired $\mathrm{CO}_{2}\left(\mathrm{P}_{\overline{\mathrm{ECO}}}\right)$ by exhaled gas collection and analysis, use of a metabolic analyzer, or use of a volumetric $\mathrm{CO}_{2}$ monitor. The Dräger $\mathrm{XL}$ ventilator is equipped with integrated volumetric $\mathrm{CO}_{2}$ monitoring and calculates minute $\mathrm{CO}_{2}$ production $\left(\overline{\mathbf{V}}_{\mathrm{CO}_{2}}\right)$. We calculated $\mathbf{P}_{\overline{\mathrm{ECO}}}$ and $\mathrm{V}_{\mathrm{D}} / \mathrm{V}_{\mathrm{T}}$ from ventilator derived volumetric $\mathrm{CO}_{2}$ measurements of $\overline{\mathrm{V}}_{\mathrm{CO}_{2}}$ and compared them to metabolic analyzer and volumetric $\mathrm{CO}_{2}$ monitor measurements. METHODS: A total of 67 measurements in 36 subjects recovering from acute lung injury or ARDS were compared. Thirty-one ventilator derived measurements were compared to measurements using 3 different metabolic analyzers, and 36 ventilator derived measurements were compared to measurements from a volumetric $\mathrm{CO}_{2}$ monitor. RESULTS: There was a strong agreement between ventilator derived measurements and metabolic analyzer or volumetric $\mathrm{CO}_{2}$ monitor measurements of $\mathrm{P}_{\overline{\mathrm{ECO}}}$ and $\mathrm{V}_{\mathrm{D}} / \mathrm{V}_{\mathrm{T}}$. The correlations, bias, and precision between the ventilator and metabolic analyzer measurements for $\mathrm{P}_{\overline{\mathrm{E} C O}}$ were $\mathrm{r}=0.97, \mathrm{r}^{2}=0.93(P<.001)$, bias $-1.04 \mathrm{~mm} \mathrm{Hg}$, and precision $\pm 1.47 \mathrm{~mm} \mathrm{Hg}$. For $\mathrm{V}_{\mathrm{D}} / \mathrm{V}_{\mathrm{T}}$ the correlations were $\mathrm{r}=0.95$ and $\mathrm{r}^{2}=0.91(P<.001)$, and the bias and precision were $0.02 \pm 0.04$. The correlations between the ventilator and the volumetric $\mathrm{CO}_{2}$ monitor for $\mathrm{P}_{\overline{\mathrm{ECO}}}$ were $r=0.96$ and $r^{2}=0.92(P<.001)$, and the bias and precision were $-0.19 \pm 1.58 \mathrm{~mm} \mathrm{Hg}$. The correlations between the ventilator and the volumetric $\mathrm{CO}_{2}$ monitor for $\mathrm{V}_{\mathrm{D}} / \mathrm{V}_{\mathrm{T}}$ were $\mathrm{r}=0.97$ and $\mathrm{r}^{2}=0.95(P<.001)$, and the bias and precision were $0.01 \pm 0.03$. CONCLUSIONS: $\mathrm{P}_{\overline{\mathrm{ECO}}}$, and therefore $V_{D} / V_{T}$, can be accurately calculated directly from the Dräger $X L$ ventilator volumetric capnography measurements without use of a metabolic analyzer or volumetric $\mathrm{CO}_{2}$ monitor. Key words: dead space fraction; metabolic analyzer; volumetric $\mathrm{CO}_{2}$ monitor; ventilator; volumetric capnography; volumetric capnogram. [Respir Care 2013;58(7):1143-1151. (C) 2013 Daedalus Enterprises]
\end{abstract}

\section{Introduction}

Dead-space ventilation, the portion of a tidal volume that does not contribute to gas exchange, was first described and calculated by the Bohr equation in $1891,{ }^{1}$ and later by the Enghoff modification of the Bohr equation in

The authors are affiliated with Respiratory Care Services, Department of Anesthesia and Perioperative Care, San Francisco General Hospital, University of California, San Francisco, California.

The authors have disclosed no conflicts of interest.

Mr Siobal presented a version of this paper at the 56th AARC Congress, held December 6-9, 2010, in Las Vegas, Nevada.
1938. ${ }^{2}$ Physiologic dead-space fraction (dead space divided by tidal volume $\left[\mathrm{V}_{\mathrm{D}} / \mathrm{V}_{\mathrm{T}}\right]$ ), as defined by Bohr and Enghoff, is the sum of anatomic or airway dead space $\left(\mathrm{V}_{\mathrm{D} \text {-anat }}\right)$ and alveolar dead space $\left(\mathrm{V}_{\mathrm{D} \text {-alv }}\right)$ divided by the $\mathrm{V}_{\mathrm{T}}$. The definition of pure dead space is ventilation without perfusion, whereby alveolar gases do not contact blood flowing through the pulmonary capillaries. All conducting airways (anatomical and mechanical dead space), areas of

\footnotetext{
Correspondence: Mark S Siobal RRT FAARC, Respiratory Care Services, San Francisco General Hospital, 1001 Potrero Avenue, NH GA2, San Francisco CA 94110. E-mail: msiobal@sfghsom.ucsf.edu.
}

DOI: $10.4187 /$ respcare. 02116 
pure shunt (pulmonary capillary perfusion with no ventilation), areas of pure dead space, and the presence of gas exchange units with any degree of inequality of ventilation in relation to perfusion, can contribute to the calculated dead-space ventilation.

Assessing $\mathrm{V}_{\mathrm{D}} / \mathrm{V}_{\mathrm{T}}$ in critically ill patients during mechanical ventilation is important for several reasons. ${ }^{3}$ The prognostic value of $\mathrm{V}_{\mathrm{D}} / \mathrm{V}_{\mathrm{T}}$ has been linked to mortality risk in $\mathrm{ARDS}^{4-7}$ and to other important clinical indices. $\mathrm{V}_{\mathrm{D}} / \mathrm{V}_{\mathrm{T}}$ is known to correlate with the severity of lung injury, ${ }^{8-12}$ can be useful as an indicator of lung recruitment versus overdistention in patients with acute lung injury (ALI) and ARDS, ${ }^{13-17}$ may be helpful as a predictor of successful extubation in pediatric ${ }^{18}$ and adult patients, ${ }^{19}$ and may be useful in diagnosing and assessing the severity of pulmonary embolism. ${ }^{20,21}$

See the Related Editorial on Page 1258

Simplified bedside calculation of $\mathrm{V}_{\mathrm{D}} / \mathrm{V}_{\mathrm{T}}$ requires a measurement of the partial pressure of mean expired $\mathrm{CO}_{2}$ $\left(\mathrm{P}_{\overline{\mathrm{E} C O}}{ }_{2}\right)$ and use of the Enghoff modification of the Bohr equation. ${ }^{2}$ The Enghoff equation differs from the original Bohr equation by the substitution of $\mathrm{P}_{\mathrm{aCO}}$ for the partial pressure of mixed alveolar $\mathrm{CO}_{2}\left(\mathrm{P}_{\mathrm{ACO}_{2}}\right)$. The Enghoff equation became the standard in clinical practice for calculation of $\mathrm{V}_{\mathrm{D}} / \mathrm{V}_{\mathrm{T}}$ because $\mathrm{P}_{\mathrm{ACO}_{2}}$ has been difficult to accurately measure or estimate at the bedside. The traditional technique of measuring $\mathrm{P}_{\overline{\mathrm{ECO}}}$ used the Douglas bag method of exhaled gas collection and analysis. ${ }^{22}$ Technological advancements allow the use of a metabolic analyzer, ${ }^{23,24}$ and, more recently, use of volumetric capnography and a volumetric $\mathrm{CO}_{2}$ monitor. ${ }^{25}$

The Dräger XL ventilator (Dräger Medical, Telford, Pennsylvania) is equipped with integrated $\mathrm{CO}_{2}$ and volume measurement capabilities (volumetric $\mathrm{CO}_{2}$ ). We calculated $\mathrm{P}_{\overline{\mathrm{E} C O}}$ and $\mathrm{V}_{\mathrm{D}} / \mathrm{V}_{\mathrm{T}}$ directly from the Dräger $\mathrm{XL}$ ventilator volumetric $\mathrm{CO}_{2}$ measurements of $\overline{\mathrm{V}}_{\mathrm{CO}_{2}}$ and compared them to metabolic analyzer and volumetric $\mathrm{CO}_{2}$ monitor measurements of $\mathrm{P}_{\overline{\mathrm{ECO}}}$ and $\mathrm{V}_{\mathrm{D}} / \mathrm{V}_{\mathrm{T}}$.

\section{Methods}

A total of 67 measurements were performed in 36 subjects who met the American-European Consensus Conference criteria for ALI or ARDS. ${ }^{26}$ Measurement were done at varying time periods after ALI or ARDS criteria were met (Table 1). Phase 1 of the study compared 31 ventilator derived measurements in 25 subjects to measurements from 3 different metabolic analyzers:, Metascope (Cybermedic, Louisville, Colorado, $n=9$ ), Deltatrac (SensorMedics, Yorba Linda, California, $n=4$ ), and Vmax Encore (Via-

\section{QUICK LOOK}

\section{Current knowledge}

Measurement of the ratio of physiologic dead space $\left(\mathrm{V}_{\mathrm{D}}\right)$ to tidal volume $\left(\mathrm{V}_{\mathrm{T}}\right)$ with mixed expired carbon dioxide and blood gas analysis can be accomplished with various commercially available monitors. In acute respiratory distress syndrome, higher $\mathrm{V}_{\mathrm{D}} / \mathrm{V}_{\mathrm{T}}$ is associated with higher mortality.

\section{What this paper contributes to our knowledge}

$\mathrm{V}_{\mathrm{D}} / \mathrm{V}_{\mathrm{T}}$ was accurately measured by volumetric capnography on the Dräger XL ventilator, compared with 3 metabolic analyzers (Metascope, Deltatrac, and Vmax Encore) and the NICO monitor. Volumetric capnography on the Dräger XL ventilator obviates the use of a stand-alone analyzer for measuring $\mathrm{V}_{\mathrm{D}} / \mathrm{V}_{\mathrm{T}}$.

sys, Yorba Linda, California, $n=18$ ). Use of the various metabolic analyzers was based on functional availability. All metabolic analyzers used were maintained by annual biomedical engineering preventive maintenance and performance verification. In phase 2 of the study, 36 ventilator derived measurements in 11 subjects were compared to the $\mathrm{NICO}_{2}$ Respiratory Profile Monitor (Philips Healthcare, Andover, Massachusetts).

$\mathrm{V}_{\mathrm{D}} / \mathrm{V}_{\mathrm{T}}$ measurements were performed when requested by the ICU team. Arterial blood gas samples for $\mathrm{P}_{\mathrm{aCO}_{2}}$ determination and $\mathrm{V}_{\mathrm{D}} / \mathrm{V}_{\mathrm{T}}$ calculation were obtained from arterial catheters. Prior to all measurements, ventilator, metabolic analyzer, and $\mathrm{NICO}_{2}$ monitor $\mathrm{CO}_{2}$ and flow sensors were calibrated using the manufacturers' specifications. Following all ventilator circuit disconnections, approximately $30 \mathrm{~min}$ was allowed for patient stabilization. Ventilator measurements were done simultaneously during metabolic analyzer and $\mathrm{NICO}_{2}$ monitor measurements, for comparison. The ventilator circuit was checked for leaks, and patients with active pulmonary air leaks were excluded from the study. The study was approved by the Committee on Human Research at the University of California, San Francisco.

\section{Ventilator Volumetric $\mathrm{CO}_{2}$ Measurements}

The Dräger XL ventilator's mainstream $\mathrm{CO}_{2}$ sensor was placed between the ventilator circuit and the patient connection. The ventilator expiratory flow sensor positioned at the distal side of the expiratory valve measured exhaled $\mathrm{V}_{\mathrm{T}}$ and exhaled minute ventilation $\left(\dot{\mathrm{V}}_{\mathrm{E}}\right)$. Ventilator volumetric $\mathrm{CO}_{2}$ measurements were initiated and displayed on 


\section{Calculation of Physiologic Dead Space}

Table 1. Subject Characteristics

\begin{tabular}{lc}
\hline \hline Female/male & $8 / 28$ \\
Age, mean \pm SD y & $49.4 \pm 14.5$ \\
ALI/ARDS, mean \pm SD days* & $7.9 \pm 3.8$ \\
ALI/ARDS etiology & \\
Pneumonia & 8 \\
Trauma & 17 \\
Burns & 3 \\
Sepsis & 5 \\
Pancreatitis & 3
\end{tabular}

* Number of days after ARDS protocol initiated and study data collected.

ALI $=$ acute lung injury sampling line at the ventilator expired gas outlet (Vmax Encore). After a stable 10-min measurement period, $\mathrm{F}_{\mathrm{ECO}_{2}}$ averaged over a $5 \mathrm{~min}$ period from the metabolic analyzer was used to calculate $\mathrm{P}_{\overline{\mathrm{ECO}}}$, using equation 2 above.

All metabolic analyzer measurements of $\mathrm{P}_{\overline{\mathrm{ECO}}}$ were corrected for circuit compression volume, as previously described, ${ }^{23-25,27-29}$ whereby the $\mathrm{P}_{\overline{\mathrm{ECO}}}$ was multiplied by the ratio of the observed $\mathrm{V}_{\mathrm{T}}$ divided by the observed $\mathrm{V}_{\mathrm{T}}$ minus the calculated compression volume using the following equations:

Compression volume $=($ peak inspiratory pressure -

$$
\text { PEEP) } \times \text { circuit compliance }
$$

$$
\text { Corrected } \begin{aligned}
\mathrm{P}_{\overline{\mathrm{ECO}}} & =\mathrm{P}_{\overline{\mathrm{E} C O}} \\
& \times\left(\mathrm{V}_{\mathrm{T}} /\left[\mathrm{V}_{\mathrm{T}}-\text { compression volume }\right]\right)
\end{aligned}
$$

over $5 \mathrm{~min}$. All measurements were reported at body temperature, and pressure, saturated (BTPS).

The fraction of exhaled $\mathrm{CO}_{2}\left(\mathrm{~F}_{\mathrm{ECO}_{2}}\right)$ was calculated manually by dividing the ventilator derived $\dot{\mathrm{V}}_{\mathrm{CO}_{2}}$ by the $\dot{\mathrm{V}}_{\mathrm{E}}$ :

$$
\mathrm{F}_{\mathrm{ECO}_{2}}=\dot{\mathrm{V}}_{\mathrm{CO}_{2}} / \dot{\mathrm{V}}_{\mathrm{E}}
$$

$\mathrm{P}_{\overline{\mathrm{E} C O}}$ was then calculated by multiplying $\mathrm{F}_{\mathrm{ECO}_{2}}$ by the barometric pressure minus water vapor pressure:

$$
\mathrm{P}_{\overline{\mathrm{ECO}}_{2}}=\mathrm{F}_{\mathrm{ECO}_{2}} \times(760-47)
$$

$\mathrm{P}_{\overline{\mathrm{ECO}}_{2}}$ was then used to calculate $\mathrm{V}_{\mathrm{D}} / \mathrm{V}_{\mathrm{T}}$ by the Enghoff modification of the Bohr equation:

$$
\mathrm{V}_{\mathrm{D}} / \mathrm{V}_{\mathrm{T}}=\left(\mathrm{P}_{\mathrm{aCO}_{2}}-\mathrm{P}_{\overline{\mathrm{ECO}}_{2}}\right) / \mathrm{P}_{\mathrm{aCO}_{2}}
$$

The automated ventilator correction for delivered and measured $\mathrm{V}_{\mathrm{T}}$ was used by performing a circuit compliance test at device startup. The automated ventilator correction adjusts the delivered and measured $\mathrm{V}_{\mathrm{T}}$, and therefore the ventilator calculated values for $\dot{\mathrm{V}}_{\mathrm{CO}_{2}}$ and $\dot{\mathrm{V}}_{\mathrm{E}}$ reflect the adjusted values and eliminate the need for a manual circuit compression volume correction.

\section{Metabolic Analyzer Measurements}

The metabolic analyzers were warmed up for $20 \mathrm{~min}$ and calibrated per the manufacturers' recommendations. The inspired gases were sampled from the ventilator's inspiratory limb, and the exhaled gases and volumes were measured by directing expiratory gas flow into the metabolic analyzer (Metascope and Deltatrac) or by placement of the metabolic analyzer flow sensor and expired gas
Ventilator circuit compliance factors of 2.5 and $2.0 \mathrm{~mL} /$ $\mathrm{cm} \mathrm{H}_{2} \mathrm{O}$ were used pre and post a ventilator circuit configuration change that was implemented during the study period. The circuit compliance factor of $2.5 \mathrm{~mL} / \mathrm{cm} \mathrm{H}_{2} \mathrm{O}$ was used for the Metascope and Deltatrac, and $2.0 \mathrm{~mL} /$ $\mathrm{cm} \mathrm{H}_{2} \mathrm{O}$ was used for the Vmax Encore. Circuit compression volume was determined by laboratory testing and confirmed by the ventilator circuit compliance test mentioned above. $\mathrm{V}_{\mathrm{T}}$ was derived by dividing the $\dot{\mathrm{V}}_{\mathrm{E}}$ by the breathing frequency measured by the metabolic analyzer. The Dräger XL ventilator uses a non-bias-flow triggering method, and therefore additional correction for potential measurement error caused by bias flow was unnecessary.

\section{$\mathrm{NICO}_{2}$ Monitor Measurements}

The $\mathrm{NICO}_{2}$ monitor combined $\mathrm{CO}_{2}$ /flow sensor was allowed to warm up for 5 min until stable measurements for $\mathrm{P}_{\overline{\mathrm{ECO}}}$ were obtained. Both the $\mathrm{NICO}_{2}$ combined sensor and the ventilator mainstream $\mathrm{CO}_{2}$ sensor were placed between the ventilator circuit and the subject. The $\mathrm{NICO}_{2}$ sensor and the ventilator $\mathrm{CO}_{2}$ sensor were placed distal and proximal to each other in random order. In a previous bench study, the distal or proximal position of either sensor did not result in position related bias. ${ }^{30} \mathrm{P}_{\overline{\mathrm{ECO}}}$ derived from the ventilator measurements was rounded to the nearest whole number for comparison to the $\mathrm{NICO}_{2}$ monitor display of $\mathrm{P}_{\overline{\mathrm{E} C O}}$.

Since the $\mathrm{NICO}_{2}$ combined $\mathrm{CO}_{2}$ /flow sensor measures distal to the ventilator Y-piece, the effects of ventilator circuit compression volume and the utilization of a correction factor are unnecessary. 


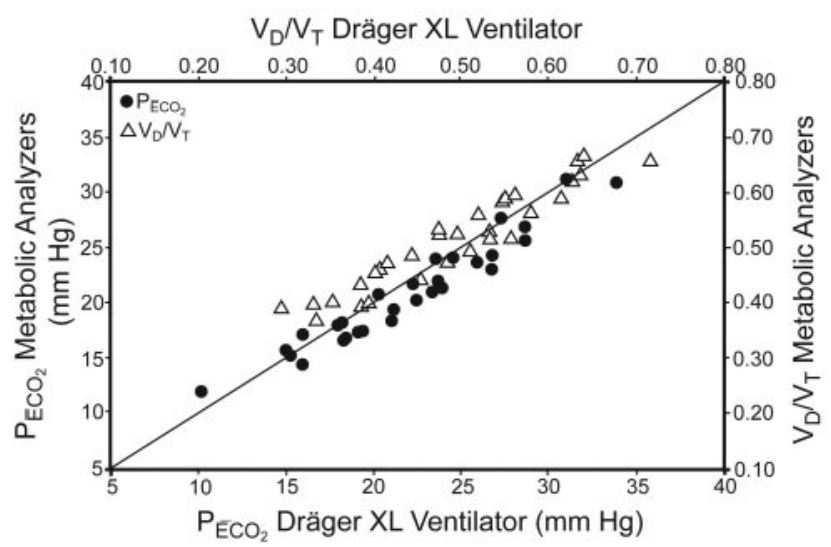

Fig. 1. Correlation of partial pressure of mean expired $\mathrm{CO}_{2}\left(\mathrm{P}_{\overline{\mathrm{ECO}}}\right)$ and ratio of dead space to tidal volume $\left[\mathrm{V}_{\mathrm{D}} / \mathrm{V}_{\mathrm{T}}\right]$ between the Dräger XL ventilator and 3 different metabolic analyzers, plotted against the line of identity. For $\mathrm{P}_{\mathrm{ECO}_{2}}, r=0.97$ and $r^{2}=0.93$ $(P<.001)$. For $\mathrm{V}_{\mathrm{D}} / \mathrm{V}_{\mathrm{T}}, \mathrm{r}=0.95$ and $\mathrm{r}^{2}=0.91(P<.001)$.

\section{Statistical Analysis}

The ventilator derived measurements of $\dot{\mathrm{V}}_{\mathrm{CO}_{2}}, \mathrm{~F}_{\mathrm{ECO}_{2}}$, $\mathrm{P}_{\overline{\mathrm{E} C O}_{2}}$, and $\mathrm{V}_{\mathrm{D}} / \mathrm{V}_{\mathrm{T}}$ were compared to the metabolic analyzer measurements. The $\mathrm{P}_{\overline{\mathrm{ECO}}}$ and $\mathrm{V}_{\mathrm{D}} / \mathrm{V}_{\mathrm{T}}$ derived from ventilator measurements were compared to the $\mathrm{NICO}_{2}$ monitor measurements. The data were compared and analyzed by correlation measured by the Pearson productmoment correlation coefficient (r) and the coefficient of determination $\left(\mathrm{r}^{2}\right)$. Bias and precision were assessed by Bland-Altman analysis. Statistical analysis was done using commercially available software (Excel, 14.2.2, Microsoft, Redmond, Washington). Correlation results were considered to be significant when $P<.05$.

\section{Results}

There was a strong correlation, agreement, and accuracy between the ventilator derived measurements and the metabolic analyzer or volumetric $\mathrm{CO}_{2}$ monitor measurements of $\dot{\mathrm{V}}_{\mathrm{CO}_{2}}, \mathrm{~F}_{\mathrm{ECO}_{2}}, \mathrm{P}_{\overline{\mathrm{ECO}}}$, and $\mathrm{V}_{\mathrm{D}} / \mathrm{V}_{\mathrm{T}}$.

In phase 1 of the study, the correlations between the ventilator derived measurements and the metabolic analyzer measurements for $\dot{\mathrm{V}}_{\mathrm{CO}_{2}}$ and $\mathrm{F}_{\mathrm{ECO}_{2}}$ were $\mathrm{r}=0.92$ and $\mathrm{r}^{2}=0.85(P<.001)$, and $\mathrm{r}=0.95$ and $\mathrm{r}^{2}=0.91$ $(P<.001)$. The bias and precision for $\dot{\mathrm{V}}_{\mathrm{CO}_{2}}$ and $\mathrm{F}_{\mathrm{ECO}_{2}}$ were $24 \pm 31 \mathrm{~mL} / \mathrm{min}$ and $0.07 \pm 0.23 \%$, respectively. The correlations for $\mathrm{P}_{\overline{\mathrm{E} C O}}$ were $\mathrm{r}=0.97$ and $\mathrm{r}^{2}=0.93$ $(P<.001)$ (Fig. 1), and the bias and precision were $-1.04 \pm 1.47 \mathrm{~mm} \mathrm{Hg}$ (Fig. 2). The correlations for $\mathrm{V}_{\mathrm{D}} / \mathrm{V}_{\mathrm{T}}$ were $\mathrm{r}=0.95$ and $\mathrm{r}^{2}=0.91(P<.001)$ (see Fig. 1), and the bias and precision were $0.02 \pm 0.04$ (Fig. 3). The $P$ value of 2 tailed probability for the Pearson correlation

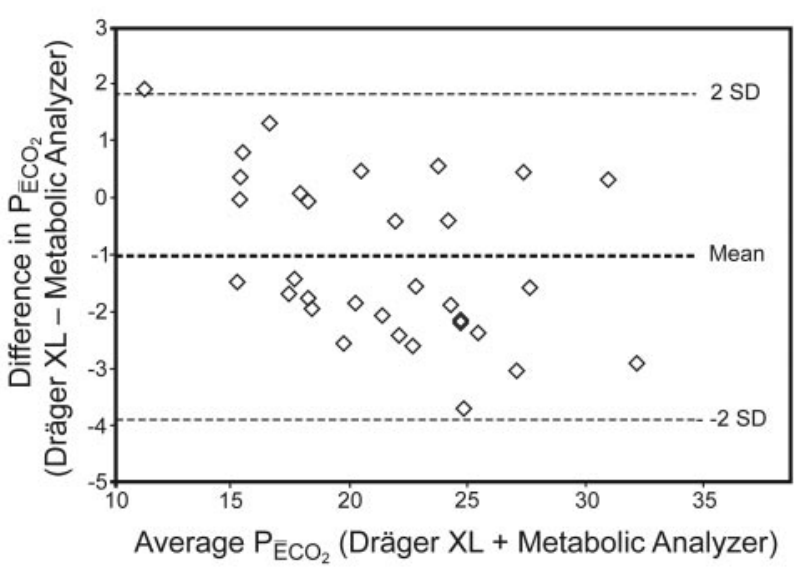

Fig. 2. Bland-Altman plot comparing partial pressure of mean expired $\mathrm{CO}_{2}\left(\mathrm{P}_{\mathrm{ECO}_{2}}\right)$ calculated by measurements from the Dräger $\mathrm{XL}$ ventilator and 3 different metabolic analyzers. The bias and precision are $-1.04 \pm 1.47 \mathrm{~mm} \mathrm{Hg}(95 \% \mathrm{Cl}-3.91$ to $1.84 \mathrm{~mm} \mathrm{Hg})$.

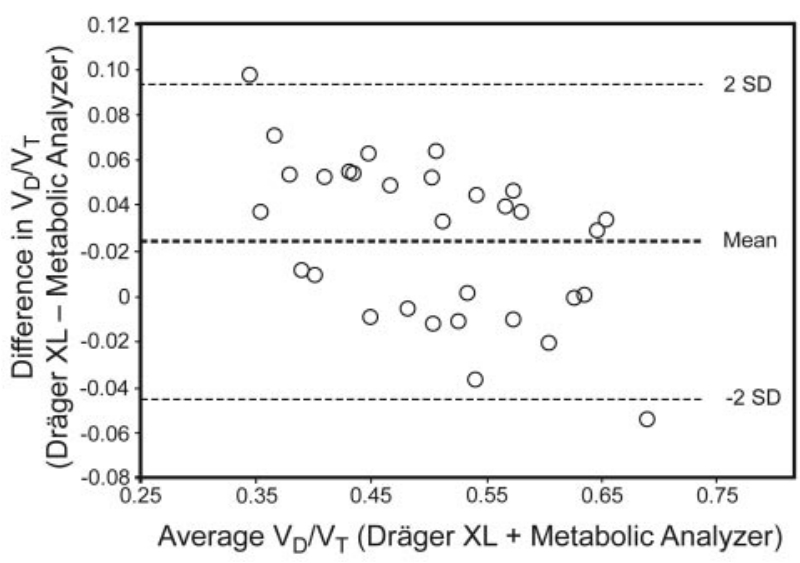

Fig. 3. Bland-Altman plot comparing the ratio of dead space to tidal volume $\left[\mathrm{V}_{\mathrm{D}} / \mathrm{V}_{\mathrm{T}}\right]$, calculated by measurements from the Dräger XL ventilator and 3 different metabolic analyzers. The bias and precision are $0.02 \pm 0.04(95 \% \mathrm{Cl}-0.05$ to 0.09$)$.

coefficient reached statistical significance for each metabolic analyzer for both $\mathrm{P}_{\overline{\mathrm{E} C O}}$ and $\mathrm{V}_{\mathrm{D}} / \mathrm{V}_{\mathrm{T}}$, except for one where the sample size was very small (DeltaTrac, $n=4$, $\left.\mathrm{V}_{\mathrm{D}} / \mathrm{V}_{\mathrm{T}}, P=.09\right)$. Similarly, bias and precision remained within clinically acceptable ranges when individual measurements between the 3 metabolic analyzers were compared to the combined data from all 3 analyzers (Table 2).

In phase 2 of the study, the correlations, between the ventilator and the volumetric $\mathrm{CO}_{2}$ monitor measurements for $\mathrm{P}_{\overline{\mathrm{ECO}}}$ were $\mathrm{r}=0.96$ and $\mathrm{r}^{2}=0.92(P<.001)$ (Fig. 4), and the bias and precision were $-0.19 \pm 1.58 \mathrm{~mm} \mathrm{Hg}$ (Fig. 5), and for $\mathrm{V}_{\mathrm{D}} / \mathrm{V}_{\mathrm{T}}$ the correlations were $\mathrm{r}=0.97$ and $\mathrm{r}^{2}=0.95(P<.001)$ (see Fig. 4), and the bias and precision were $0.01 \pm 0.03$ (Fig. 6). 
Table 2. Correlation, Bias, and Precision Between Individual Metabolic Analyzers, Compared to the Combined Data From All 3 Analyzers

\begin{tabular}{|c|c|c|c|c|c|}
\hline & $\begin{array}{c}\text { Correlation } \\
\text { Coefficient } \\
\text { r }\end{array}$ & $\begin{array}{c}\text { Coefficient of } \\
\text { Determination } \\
\mathrm{r}^{2}\end{array}$ & $P$ & Bias & Precision \\
\hline \multicolumn{6}{|c|}{$\begin{array}{c}\text { Combined data } \\
\qquad(n=31)\end{array}$} \\
\hline $\mathrm{V}_{\mathrm{D}} / \mathrm{V}_{\mathrm{T}}$ & 0.95 & 0.91 & $<.001$ & 0.02 & 0.04 \\
\hline $\mathrm{P}_{\overline{\mathrm{E} C O}}$ & 0.97 & 0.93 & $<.001$ & -1.04 & 1.47 \\
\hline \multicolumn{6}{|c|}{$\begin{array}{l}\text { Metascope } \\
\qquad(n=9)\end{array}$} \\
\hline $\mathrm{V}_{\mathrm{D}} / \mathrm{V}_{\mathrm{T}}$ & 0.98 & 0.96 & $<.001$ & 0.01 & 0.02 \\
\hline $\mathrm{P}_{\overline{\mathrm{ECO}}_{2}}$ & 0.98 & 0.97 & $<.001$ & -1.39 & 0.91 \\
\hline \multicolumn{6}{|c|}{$\begin{array}{l}\text { Deltatrac } \\
\qquad(n=4)\end{array}$} \\
\hline $\mathrm{V}_{\mathrm{D}} / \mathrm{V}_{\mathrm{T}}$ & 0.91 & 0.82 & .09 & 0.01 & 0.03 \\
\hline $\mathrm{P}_{\overline{\mathrm{E}} \mathrm{CO}_{2}}$ & 0.96 & 0.93 & .04 & -0.84 & 1.69 \\
\hline \multicolumn{6}{|c|}{$\begin{array}{l}\operatorname{Vmax} \\
\qquad(n=18)\end{array}$} \\
\hline $\mathrm{V}_{\mathrm{D}} / \mathrm{V}_{\mathrm{T}}$ & 0.97 & 0.94 & $<.001$ & 0.04 & 0.04 \\
\hline $\mathrm{P}_{\overline{\mathrm{ECO}}_{2}}$ & 0.98 & 0.95 & $<.001$ & -1.50 & 1.49 \\
\hline
\end{tabular}

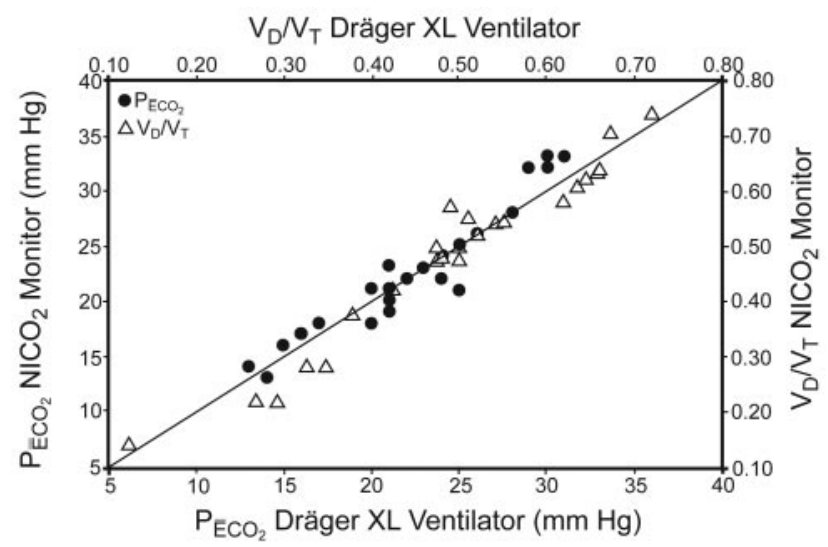

Fig. 4. Correlation of partial pressure of mean expired $\mathrm{CO}_{2}\left(\mathrm{P}_{\overline{\mathrm{ECO}}}\right)$ and ratio of dead space to tidal volume $\left[\mathrm{V}_{\mathrm{D}} / \mathrm{V}_{\mathrm{T}}\right]$ between the Dräger $\mathrm{XL}$ ventilator and the $\mathrm{NICO}_{2}$ volumetric $\mathrm{CO}_{2}$ monitor, plotted against the line of identity. For $\mathrm{P}_{\mathrm{ECO}_{2}}, r=0.96$ and $r^{2}=0.92$ $(P<.001)$. For $\mathrm{V}_{\mathrm{D}} / \mathrm{V}_{\mathrm{T}}, \mathrm{r}=0.97$ and $\mathrm{r}^{2}=0.95(P<.001)$.

\section{Discussion}

The results of this study confirm that $\mathrm{P}_{\overline{\mathrm{ECO}}}$, and therefore $V_{D} / V_{T}$, using the Enghoff equation can be accurately calculated directly from the Dräger XL ventilator's volumetric capnography measurements, without use of a metabolic analyzer or volumetric $\mathrm{CO}_{2}$ monitor. In a recent study, use of volumetric capnography calculations of $\mathrm{V}_{\mathrm{D}} / \mathrm{V}_{\mathrm{T}}$ from the Dräger XL ventilator were shown to be a predic-

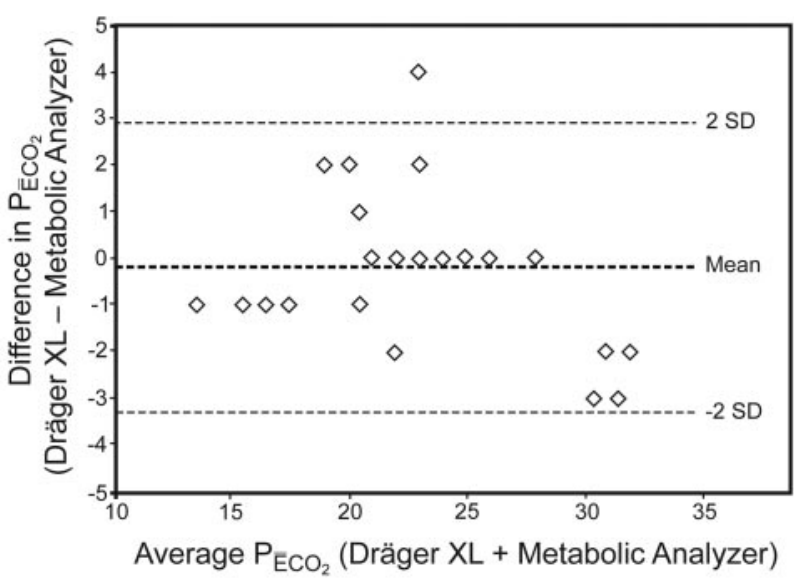

Fig. 5. Bland-Altman plot comparing partial pressure of mean expired $\mathrm{CO}_{2}\left(\mathrm{P}_{\overline{\mathrm{ECO}}}\right)$ calculated by measurements from the Dräger $\mathrm{XL}$ ventilator and the $\mathrm{NICO}_{2}$ volumetric $\mathrm{CO}_{2}$ monitor. The bias and precision are $-0.19 \pm 1.58 \mathrm{~mm} \mathrm{Hg}(95 \% \mathrm{Cl}-3.30$ to $2.91 \mathrm{~mm} \mathrm{Hg})$.

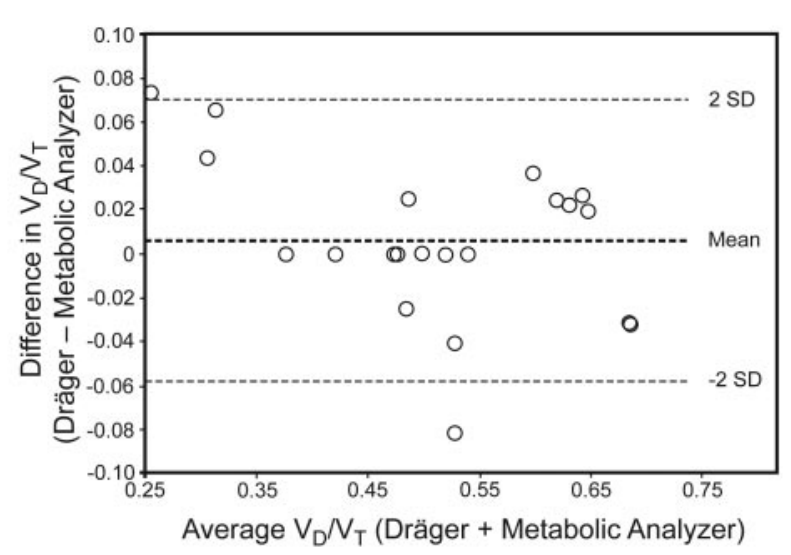

Fig. 6. Bland-Altman plot comparing the ratio of dead space to tidal volume $\left[\mathrm{V}_{\mathrm{D}} / \mathrm{V}_{\mathrm{T}}\right.$ ] calculated by measurements from the Dräger $\mathrm{XL}$ ventilator and the $\mathrm{NICO}_{2}$ volumetric $\mathrm{CO}_{2}$ monitor. The bias and precision are $0.01 \pm 0.03$ (95\% Cl 0.01-0.03).

tor of extubation success. ${ }^{19}$ However, to our knowledge the results of our study are the first to validate the accuracy of the Dräger XL measurements of $\mathrm{V}_{\mathrm{D}} / \mathrm{V}_{\mathrm{T}}$ against previously accepted methods.

These findings have several important implications. This simplified approach to $\mathrm{V}_{\mathrm{D}} / \mathrm{V}_{\mathrm{T}}$ measurement will improve availability, allow early and repeated measurements, and will increase the utilization of $\mathrm{V}_{\mathrm{D}} / \mathrm{V}_{\mathrm{T}}$ for prognostic, diagnostic, and disease severity monitoring in the critical care setting. $\mathrm{V}_{\mathrm{D}} / \mathrm{V}_{\mathrm{T}}$ has been shown to be predictive of the mortality risk in patients with ARDS in both the early and intermediate phases of the disease progression in single center or small cohort studies.4-8 Patients with $\mathrm{V}_{\mathrm{D}}$ / $\mathrm{V}_{\mathrm{T}} \geq 0.57$ were found to have higher mortality, with a $45 \%$ increase in the odds of dying for every 0.05 increase 


\section{Calculation of Physiologic Dead Space}

Table 3. Correlation, Bias, and Precision From Studies That Compared Different Methods for Calculating the Ratio of Dead Space to Tidal Volume Using the Enghoff Equation

\begin{tabular}{|c|c|c|c|c|}
\hline & $\begin{array}{c}\text { Correlation } \\
\mathrm{r}\end{array}$ & Bias & Precision & Study \\
\hline Metabolic analyzer vs Dräger XL & 0.95 & 0.02 & 0.04 & Present study \\
\hline $\mathrm{NICO}_{2}$ monitor vs Dräger XL & 0.97 & 0.01 & 0.03 & Present study \\
\hline Douglas bag vs metabolic analyzer & 0.92 & 0.01 & 0.03 & MacKinnon $^{23}$ \\
\hline Douglas bag vs metabolic analyzer & 0.99 & -0.02 & 0.01 & $\operatorname{Lum}^{24}$ \\
\hline Metabolic analyzer vs $\mathrm{NICO}_{2}$ monitor & 0.94 & 0.02 & 0.05 & Kallet $^{25}$ \\
\hline
\end{tabular}

in dead-space fraction. ${ }^{5} \mathrm{~V}_{\mathrm{D}} / \mathrm{V}_{\mathrm{T}}$ is also known to be a marker of the severity of lung injury. ${ }^{9-13}$ Serial monitoring of $\mathrm{V}_{\mathrm{D}} / \mathrm{V}_{\mathrm{T}}$ over the duration and course of ALI/ARDS can be useful as a means to assess the need and effects of supportive therapeutic strategies and interventions. ${ }^{12,13} \mathrm{~V}_{\mathrm{D}} / \mathrm{V}_{\mathrm{T}}$ measurements in patients with ALI/ARDS have been found to be useful for titrating PEEP and optimizing cardiopulmonary function, ${ }^{14-16}$ and may be useful as a tool to monitor lung recruitment versus overdistention. ${ }^{17}$ Assessment of $\mathrm{V}_{\mathrm{D}} / \mathrm{V}_{\mathrm{T}}$ may also be used to predict successful extubation in pediatric ${ }^{18}$ and adult patients. ${ }^{19} \mathrm{~V}_{\mathrm{D}} / \mathrm{V}_{\mathrm{T}} \leq 0.50$ and $\geq 0.65$ in infants and children were found to be predictive of extubation success or failure, ${ }^{18}$ whereas in adult patients the $V_{D} / V_{T}$ cutoff value that offered the best sensitivity and specificity for predicting extubation failure was $0.58 .{ }^{19}$ $\mathrm{V}_{\mathrm{D}} / \mathrm{V}_{\mathrm{T}}$, in addition to other clinical assessments and diagnostic tests, has also been used in diagnosing and assessing the severity of pulmonary embolism..$^{20,21}$ The culmination of the broad clinical value of $\mathrm{V}_{\mathrm{D}} / \mathrm{V}_{\mathrm{T}}$ assessments in the critical care setting support the integration of this measurement into routine clinical practice.

Additionally, use of a separate standalone device for $\mathrm{V}_{\mathrm{D}} / \mathrm{V}_{\mathrm{T}}$ measurements, with the associated acquisition and supply costs and staff utilization time, may become unnecessary. Elimination of a metabolic analyzer or volumetric $\mathrm{CO}_{2}$ monitor simplifies the determination of $\mathrm{V}_{\mathrm{D}} / \mathrm{V}_{\mathrm{T}}$. Ventilator derived volumetric $\mathrm{CO}_{2}$ measurement makes physiologic dead-space fraction more accessible in clinical practice, as ventilator manufacturers incorporate volumetric $\mathrm{CO}_{2}$ monitoring capabilities into newer ventilator platforms. ${ }^{31}$ The calculations performed for his study were done manually, using ventilator derived measurements, but could easily be incorporated as an automated feature by ventilator software modification. Methods for estimating $\mathrm{V}_{\mathrm{D}} / \mathrm{V}_{\mathrm{T}}$ by predictive equations have been described using the arterial to end-tidal $\mathrm{CO}_{2}$ difference ${ }^{32,33}$ and estimation of $\overline{\mathrm{V}}_{\mathrm{CO}_{2}}{ }^{34}$ The increasing availability of volumetric capnography make the use of predictive equations unnecessary.

The results of this study are consistent with prior data that confirm the accuracy of different methods of calculating $\mathrm{V}_{\mathrm{D}} / \mathrm{V}_{\mathrm{T}}$ (Table 3). Similar correlation and accuracy of the exhaled gas collection method using a Douglas bag versus a metabolic analyzer, ${ }^{23,24}$ a metabolic analyzer versus a volumetric $\mathrm{CO}_{2}$ monitor, ${ }^{25}$ and ventilator based volumetric capnography versus a metabolic analyzer and a volumetric $\mathrm{CO}_{2}$ monitor are now demonstrated.

Limitations of this study include a relatively small sample size in each study phase, and the use of 3 different metabolic analyzers in phase 1 . Also, the ventilator circuit configuration, and therefore the circuit compression volume, were changed during the study. Despite these factors, the resiliency of the ventilator derived data in relation to the correlation, bias and precision between measurements remained consistent. Although the number of individual measurements between the 3 metabolic analyzers used varied markedly, the agreement of correlation, bias, and precision remained consistent between individual metabolic analyzers, when compared to the combined data from all 3 analyzers (see Table 2). Additionally, the change in ventilator circuit configuration and compression volume did not significantly alter the correlation and agreement of the measurements (see Table 2).

$\mathrm{V}_{\mathrm{D}} / \mathrm{V}_{\mathrm{T}}$ calculated by the original Bohr equation has been recognized as "true dead space" or the balance between effective and ineffective ventilation. The Bohr dead-space equation relies on the calculation or estimation of $\mathrm{P}_{\mathrm{ACO}_{2}}$ from mixed alveolar gas. $\mathrm{P}_{\mathrm{ACO}_{2}}$ is affected by the dilution of $\mathrm{CO}_{2}$ from the alveolar side of the alveolar-capillary membrane before the effects of shunt and venous admixture on $\mathrm{P}_{\mathrm{aCO}}$. Bohr dead space is affected by areas of high ventilation to perfusion matching, such as alveolar overdistention by excessive PEEP and/or $\mathrm{V}_{\mathrm{T}}$, pulmonary vascular occlusion, and pulmonary hypoperfusion secondary to hypovolemia. ${ }^{35}$ The Enghoff equation, on the other hand, relies on the $\mathrm{P}_{\mathrm{aCO}}$ of arterial blood and is thus an index of "true dead space" plus the effects of elevated $\mathrm{P}_{\mathrm{aCO}}$ from global gas exchange inefficiency and shunt (Fig. 7). Elevated $\mathrm{P}_{\mathrm{aCO}}$ can result from all causes of low ventilation/ perfusion matching and shunt, such as atelectasis, pneumonia, $\mathrm{COPD}$, and asthma. Furthermore, $\mathrm{P}_{\mathrm{aCO}_{2}}$ can rise when an increase in metabolic rate and $\mathrm{CO}_{2}$ production are not accompanied by an increase in $\mathrm{CO}_{2}$ excretion. Changes 


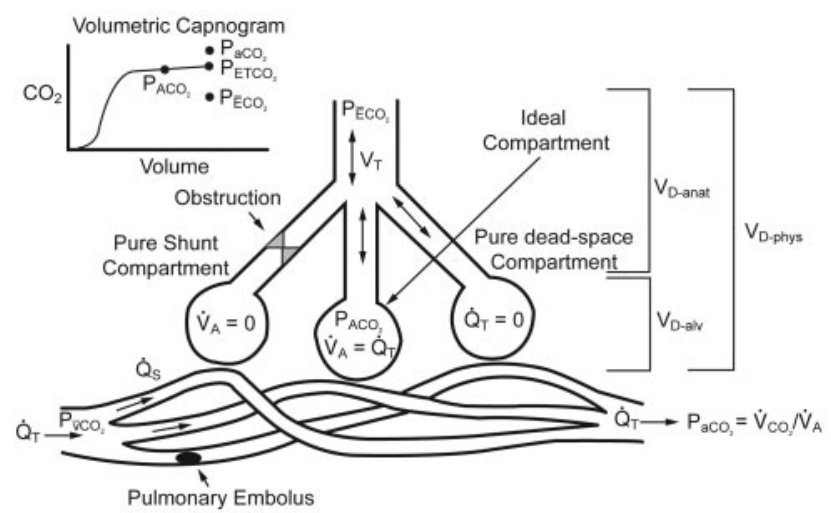

Fig. 7. The 3 compartment lung model described by Riley 36,37 represents gas exchange in the lung in regards to the matching of alveolar ventilation $\left(\dot{V}_{\mathrm{A}}\right)$ and perfusion $\left(\dot{\mathrm{Q}}_{\mathrm{T}}\right)$, shunt $\left(\dot{\mathrm{Q}}_{\mathrm{S}}\right)$, and dead space $\left(V_{D}\right)$. The ideal compartment represents areas of perfect $\dot{V}_{A}$ to $Q_{T}$ matching. The pure shunt compartment represents areas of perfusion without ventilation. The pure dead-space compartment represents areas of ventilation with no perfusion. The sum of the regions of alveolar dead space $\left(V_{D-a l v}\right)$ and anatomic dead space $\left(V_{D-a n a t}\right)$ equal the physiologic dead space $\left(V_{D-p h y s}\right)$. Dead space fraction is equal to $V_{D-p h y s}$ divided by tidal volume $\left(V_{T}\right)$. Also shown are the partial pressure of arterial carbon dioxide $\left(\mathrm{P}_{\mathrm{aCO}}\right)$, the partial pressure of venous carbon dioxide $\left(\mathrm{P}_{\mathrm{vCO}_{2}}\right)$, the relationship between $\mathrm{P}_{\mathrm{aCO}}$ and minute $\mathrm{CO}_{2}$ production $\left(\dot{\mathrm{V}}_{\mathrm{CO}_{2}}\right)$ and $\dot{\mathrm{V}}_{\mathrm{A}}$, the partial pressure of mixed alveolar carbon dioxide $\left(\mathrm{P}_{\mathrm{ACO}_{2}}\right)$, the partial pressure of end-tidal carbon dioxide $\left(\mathrm{P}_{\mathrm{ETCO}_{2}}\right)$, and the partial pressure of mean expired carbon dioxide $\left(\mathrm{P}_{\mathrm{ECO}_{2}}\right)$ in relation to the model and the volumetric capnogram. (From references 35 and 38 , with permission.)

in $\mathrm{P}_{\mathrm{aCO}_{2}}$ are determined by the relationship between $\dot{\mathrm{V}}_{\mathrm{CO}_{2}}$ and minute alveolar ventilation $\left(\dot{\mathrm{V}}_{\mathrm{A}}\right)$ whereby:

$$
\mathrm{P}_{\mathrm{aCO}_{2}}=\dot{\mathrm{V}}_{\mathrm{CO}_{2}} / \dot{\mathrm{V}}_{\mathrm{A}}
$$

If $\dot{\mathrm{V}}_{\mathrm{CO}_{2}}$ increases without a proportional rise in $\dot{\mathrm{V}}_{\mathrm{A}}, \mathrm{CO}_{2}$ production exceeds $\mathrm{CO}_{2}$ excretion and $\mathrm{P}_{\mathrm{aCO}}$ increases. Therefore the Enghoff dead-space equation can overestimate $\mathrm{V}_{\mathrm{D}} / \mathrm{V}_{\mathrm{T}}$ in the presence of shunt and regions of low ventilation/perfusion ratio (Fig. 8).

Use of volumetric capnography to determine $\mathrm{P}_{\mathrm{ACO}_{2}}$ for Bohr dead-space calculation has been demonstrated ${ }^{39}$ and validated in an animal model of lung injury. ${ }^{40} \mathrm{P}_{\mathrm{ACO}_{2}}$ measured at the mid-point of phase III of the expired volume capnogram was compared to the $\mathrm{P}_{\mathrm{ACO}_{2}}$ mathematically derived using the multiple inert gas elimination technique (MIGET). There was a close linear correlation between the 2 methods for calculating $\mathrm{P}_{\mathrm{ACO}_{2}}(\mathrm{r}=0.99, P<.001)$ and Bohr dead space $(\mathrm{r}=0.96, P<.001)$. The mean $\mathrm{P}_{\mathrm{ACO}_{2}}$ and Bohr dead space from volumetric capnography were similar to the calculations obtained by MIGET, with a mean bias of $-0.10 \mathrm{~mm} \mathrm{Hg}(95 \% \mathrm{CI}-2.18$ to $1.98 \mathrm{~mm} \mathrm{Hg}$ ) and $10 \mathrm{~mL}$ (95\% CI -44 to $64 \mathrm{~mL}$ ), respectively. Given

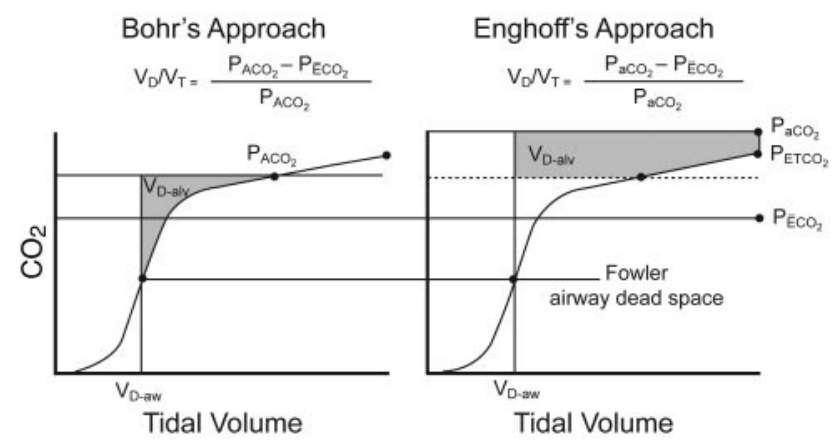

Fig. 8. Graphical representation of physiologic dead space fraction determined by volumetric capnography, using the approaches of Bohr and Enghoff, which shows how use of the Enghoff equation can overestimate alveolar dead space $\left(V_{D-a l v}\right)$ (shaded areas) by substitution of the partial pressure of arterial carbon dioxide $\left(\mathrm{P}_{\mathrm{aCO}}\right)$ for the partial pressure of mixed alveolar carbon dioxide $\left(\mathrm{P}_{\mathrm{ACO}_{2}}\right)$, determined by identifying the mid-point of phase III of the expired volumetric capnogram. ${ }^{39,40}$ Also shown are the airway or anatomical dead space $\left(\mathrm{V}_{\mathrm{D}-\mathrm{aw}}\right.$, determined by the Fowler method identified at the mid-point of phase II of the expired volumetric capnogram, $\left.{ }^{41}\right)$, the partial pressure of end-tidal carbon dioxide $\left(\mathrm{P}_{\mathrm{ETCO}_{2}}\right)$, and the partial pressure of mean expired carbon dioxide $\left(\mathrm{P}_{\overline{\mathrm{ECO}}}\right)$ in relation to the volumetric capnogram. (From reference 35, with permission.)

these findings, it has been suggested that simultaneous assessment of Bohr and Enghoff dead space using volumetric capnography may provide useful complementary information in regard to recognizing the effects of shunt and ventilation/perfusion inequality versus "true dead space" or wasted ventilation in critically ill patients with elevated $\mathrm{V}_{\mathrm{D}} / \mathrm{V}_{\mathrm{T}}{ }^{35}$ Furthermore, using volumetric capnography to determine Bohr dead space could be monitored continuously and would not require periodic arterial blood sampling to measure $\mathrm{P}_{\mathrm{aCO}} \cdot{ }^{35}$

\section{Conclusions}

This study confirms that $\mathrm{P}_{\overline{\mathrm{E} C O}}$ and $\mathrm{V}_{\mathrm{D}} / \mathrm{V}_{\mathrm{T}}$ using the Enghoff equation can be accurately calculated directly from the Dräger XL ventilator's volumetric capnography measurements, without use of a metabolic analyzer or volumetric $\mathrm{CO}_{2}$ monitor.

Future study of the use and development of ventilator based techniques for volumetric capnography measurements of $V_{D} / V_{T}$ should continue to confirm and validate measurement correlation and accuracy. Investigation of the meaningful use of continuous Bohr $\mathrm{V}_{\mathrm{D}} / \mathrm{V}_{\mathrm{T}}$ monitoring and simultaneous measurement of Bohr and Enghoff $\mathrm{V}_{\mathrm{D}} / \mathrm{V}_{\mathrm{T}}$ using volumetric capnography should also be pursued. 


\section{Calculation of Physiologic Dead Space}

\section{REFERENCES}

1. Bohr C. Über die Lungeatmung. Skand Arch Physiol 1891;2:236238. Article in German.

2. Enghoff H. Volumen inefficax: bemerkungen zur frage des schadli-chen raumes. Upsala Läkarefören Förh 1938;44:191-218. Article in German.

3. Kallet RH, Siobal MS. Measuring deadspace: does it really matter? Or, what are we waiting for? Respir Care 2010;55(3):350-352.

4. Raurich JM, Vilar M, Colomar A, Ibáñez J, Ayestarán I, PérezBárcena J, Llompart-Pou JA. Prognostic value of the pulmonary dead-space fraction during the early and intermediate phases of acute respiratory distress syndrome. Respir Care 2010;55(3):282-287.

5. Nuckton TJ, Alonso JA, Kallet RH, Daniel BM, Pittet JF, Eisner MD, Matthay MA. Pulmonary dead-space fraction as a risk factor for death in the acute respiratory distress syndrome. N Engl J Med 2002;346(17):1281-1286.

6. Kallet RH, Alonso JA, Pittet JF, Matthay MA. Prognostic value of the pulmonary dead-space fraction during the first 6 days of acute respiratory distress syndrome. Respir Care 2004;49(9):1008-1014.

7. Cepkova M, Kapur V, Ren X, Quinn T, Zhuo H, Foster E, et al. Pulmonary dead-space fraction and pulmonary artery systolic pressure as early predictors of clinical outcome in acute lung injury. Chest 2007;132(3):836-842.

8. Lucangelo U, Bernable F, Vatua S, Degrassi G, Villagra A, Fernandez R, et al. Prognostic value of different deadspace indices in mechanically ventilated patients with acute lung injury and ARDS. Chest 2008;133(1):62-71.

9. Lamy M, Fallat RJ, Koeniger E, Dietrich HP, Ratliff JL, Eberhart RC, et al. Pathologic features and mechanisms of hypoxemia in adult respiratory distress syndrome. Am Rev Respir Dis 1976;114(2):267284.

10. Ralph DD, Robertson HT, Weaver LJ, Hlastala MP, Carrico CJ, Hudson LD. Distribution of ventilation and perfusion during positive end expiratory pressure in the adult respiratory distress syndrome. Am Rev Respir Dis 1985;131(1):54-60.

11. Gattinoni L, Bombino M, Pelosi P, Lissoni A, Pesenti A, Fumagalli $\mathrm{R}$, Tagliabue M. Lung structure and function in different stages of severe adult respiratory distress syndrome. JAMA 1994;271(22): 1772-1779.

12. Bein T, Reber A, Stjernstrom H, Metz C, Taeger K, Hedenstierna G. Ventilation-perfusion ratio in patients with acute respiratory insufficiency. Anaesthesist 1996;45(4):337-342.

13. Nunes S, Valta P, Takala J. Changes in respiratory mechanics and gas exchange during the acute respiratory distress syndrome. Acta Anaesthesiol Scand 2006;50(1):80-91.

14. Suter PM, Fairley B, Isenberg MD. Optimum end-expiratory airway pressure in patients with acute pulmonary failure. N Engl J Med 1975;292(6):284-289.

15. Beydon L, Uttman L, Rawal R, Jonson B. Effects of positive endexpiratory pressure on deadspace and its partitions in acute lung injury. Intensive Care Med 2002;28(9):1239-1245.

16. Maisch S, Reissmann H, Fuellekrug B, Weismann D, Rutkowski T, Tusman G, Böhm SH. Compliance and deadspace fraction indicate an optimal level of positive end-expiratory pressure after recruitment in anesthetized patients. Anesth Analg 2008;106(1):175-181.

17. Tusman G, Suarez-Sipmann F, Böhm SH, Pech T, Reissmann H, Meschino $\mathrm{G}$, et al. Monitoring deadspace during recruitment and PEEP titration in an experimental model. Intensive Care Med 2006; 32(11): 1863-1871.

18. Hubble CL, Gentile MA, Tripp DS, Craig DM, Meliones JN, Cheifetz IM. Deadspace to tidal volume ratio predicts successful extubation in infants and children. Crit Care Med 2000;28(6):20342040.
19. González-Castro A, Suárez-Lopez V, Gómez-Marcos V, GonzálezFernandez C, Iglesias-Posadilla D, Burón-Mediavilla J, et al. Utility of the deadspace fraction $\left(\mathrm{V}_{\mathrm{D}} / \mathrm{V}_{\mathrm{T}}\right)$ as a predictor of extubation success. Med Intensiva 2011;35(9):529-538.

20. Kline JA, Kubin AK, Patel MM, Easton EJ, Seupal RA. Alveolar deadspace as a predictor of severity of pulmonary embolism. Acad Emerg Med 2000;7(6):611-617.

21. Burki NK. The deadspace to tidal volume ratio in the diagnosis of pulmonary embolism. Am Rev Respir Dis 1986;133(4):679-685.

22. Hedley-Whyte J, Pontoppidan H, Morris MJ. The response of patients with respiratory failure and cardiopulmonary disease to different levels of constant volume ventilation. J Clin Invest 1966;45(10): 1543-1554.

23. MacKinnon JC, Houston PL, McGuire GP. Validation of the Deltatrac metabolic cart for measurement of dead-space-to-tidal-volume ratio. Respir Care 1997;42(8):761-764.

24. Lum L, Saville A, Venkataraman ST. Accuracy of physiologic deadspace measurement in intubated pediatric patients using a metabolic monitor: comparison with the Douglas bag technique. Crit Care Med 1998;26(4):760-764.

25. Kallet RH, Daniel BM, Garcia O, Matthay MA. Accuracy of physiologic deadspace measurements in patients with acute respiratory distress syndrome using volumetric capnography: comparison with the metabolic monitor method. Respir Care 2005; 50(4):462-467.

26. Bernard GR, Artigas A, Brigham KL, Carlet J, Falke K, Hudson L, et al. Report of the American-European consensus conference on acute respiratory distress syndrome: definitions mechanisms, relevant outcomes, and clinical trials coordination. Am J Respir Crit Care 1994;9(1):72-81.

27. Crossman PF, Bushnell LS, Hedley-Whyte J. Dead-space during artificial ventilation: gas compression and mechanical dead-space. J Appl Physiol 1970;28(1):94-97.

28. Smith ER. Measurement of physiological deadspace during mechanical ventilation. Respir Care 1977;22(12):1341-1342.

29. Forbat AF, Her C. Correction for gas compression in mechanical ventilators. Anesth Analg 1980;59(7):488-493.

30. Siobal M, Tang J, Ong H, Toy W. Comparison of mean expired $\mathrm{CO}_{2}$ measurements calculated using the Dräger XL ventilator volumetric capnography versus the Respironics $\mathrm{NICO}_{2}$ monitor (abstract). Respir Care 2008;54(11):1560.

31. Siobal MS, Bandian L. Comparison of mean expired $\mathrm{CO}_{2}$ measurements using the eVent $7 \mathrm{i}$ ventilator volumetric capnography vs the Respironics $\mathrm{NICO}_{2}$ monitor (abstract). Respir Care 2012;57(10): 1721.

32. Frankenfield DC, Alam S, Bekteshi E, Vender RL. Predicting deadspace ventilation in critically ill patients using clinically available data. Crit Care Med 2010;38(1):288-291.

33. Hardman JG, Aitkenhead AR. Estimating alveolar deadspace from the arterial to end-tidal $\mathrm{CO}_{2}$ gradient: a modeling analysis. Anesth Analg 2003;97(6):1846-1851.

34. Siddiki H, Kojicic M, Li G, Yilmaz M, Thompson TB, Hubmayr $\mathrm{RD}$, Gajic O. Bedside quantification of dead-space fraction using routine clinical data in patients with acute lung injury: secondary analysis of two prospective trials. Crit Care 2010;14(4):R141. Erratum in: Crit Care 2011;15(2):410.

35. Tusman G, Sipmann FS, Bohm SH. Rationale of deadspace measurement by volumetric capnography. Anesth Analg 2012;114(4): 866-874.

36. Riley RL, Cournand A. Ideal alveolar air and the analysis of ventilation-perfusion relationships in the lungs. J Appl Physiol 1949; 1(12)825-847. 


\section{Calculation of Physiologic Dead Space}

37. Riley RL, Cournand A. Analysis of factors affecting partial pressures of oxygen and carbon dioxide in gas and blood of the lungs: theory. J Appl Physiol 1951;4(2):77-101.

38. Hedenstierna G, Sandhagen B. Assessing dead space: a meaningful variable? Minerva Anestesiol 2006;72(6):521-528.

39. Tusman G, Scandurra A, Böhm SH, Suarez-Sipmann F, Clara F. Model fitting of volumetric capnograms improves calculations of airway dead space and slope of phase III. J Clin Monit Comput 2009;23(4):197-206.

40. Tusman G, Suarez Sipmann F, Borges JB, Hedenstierna G, Böhm SH. Validation of Bohr deadspace measured by volumetric capnography. Intensive Care Med 2011;37(5):870-874.

41. Fowler WS. Lung function studies. II. The respiratory dead space. Am J Physiol 1948;154(3):405-416.

This article is approved for Continuing Respiratory Care Education credit. For information and to obtain your CRCE

(free to AARC members) visit

www.rcjournal.com 